\title{
Waiting for total knee replacement surgery: factors associated with pain, stiffness, function and quality of life François Desmeules*1,2, Clermont E Dionne ${ }^{\dagger 1,3}$, Étienne Belzile ${ }^{\dagger 4}$, Renée Bourbonnais ${ }^{\dagger 3,5}$ and Pierre Frémont ${ }^{\dagger 3,4}$
}

\begin{abstract}
Address: ${ }^{1}$ Population Health Research Unit (URESP), Research Centre of the Laval University Affiliated Hospital (CHA), Quebec, QC, Canada, ${ }^{2}$ Department of Social and Preventive Medicine, Faculty of Medicine, Laval University, Quebec, QC, Canada, ${ }^{3}$ Department of Rehabilitation, Care Centre (CSSS) de la Vieille Capitale, Quebec, QC, Canada

Email: François Desmeules* - francois.desmeules@uresp.ulaval.ca; Clermont E Dionne - cdionne@uresp.ulaval.ca Étienne Belzile - etienne.belzile@mail.chuq.qc.ca; Renée Bourbonnais - renee.bourbonnais@rea.ulaval.ca; Pierre Frémont - pierre.fremont@crchul.ulaval.ca

* Corresponding author †Equal contributors
\end{abstract} Faculty of Medicine, Laval University, Quebec, QC, Canada, ${ }^{4}$ Laval University Hospital (CHUQ), Quebec, QC, Canada and ${ }^{5}$ Community Health

Published: 20 May 2009

BMC Musculoskeletal Disorders 2009, 10:52 doi:10.1186/147|-2474-10-52
Received: 29 October 2008

Accepted: 20 May 2009

This article is available from: http://www.biomedcentral.com/I47I-2474/I0/52

(C) 2009 Desmeules et al; licensee BioMed Central Ltd.

This is an Open Access article distributed under the terms of the Creative Commons Attribution License (http://creativecommons.org/licenses/by/2.0), which permits unrestricted use, distribution, and reproduction in any medium, provided the original work is properly cited.

\begin{abstract}
Background: Recent evidences show that education and rehabilitation while waiting for knee replacement have positive effects on the patients' health status. Identification of factors associated with worse pain, function and health-related quality of life (HRQoL) while waiting for surgery could help develop pre-surgery rehabilitation interventions that target specifically these factors and prioritize patients that may benefit the most from them. The objectives of this study were to measure pain, stiffness, function and HRQoL in patients at enrolment on waiting lists for knee replacement and to identify demographic, clinical, socioeconomic and psychosocial characteristics associated with these outcomes.

Methods: This study is part of a broader study measuring the effects of pre-surgery wait in patients scheduled for knee replacement. From 02/2006 to 09/2007, 197 patients newly scheduled for total knee replacement were recruited from the waiting lists of three university hospitals in Quebec City, Canada. Pain, stiffness and function were measured with the Western Ontario and McMaster Osteoarthritis Index (WOMAC) and HRQoL was measured with the SF-36 Health Survey. Stepwise multiple regression analysis was used to assess the strength of the associations between the independent variables and the WOMAC and SF-36 scores.

Results: The scores of all eight HRQoL physical and mental domains of the SF-36 were significantly lower than aged matched Canadian normative data $(p<0.05)$. Contralateral knee pain, higher psychological distress, higher body mass index (BMI) and the use of a walking aid were significantly associated with worse function $(p<0.05)$ and contributed to $22 \%$ of the variance of the WOMAC function score (multiple $r=0.47$ ). A higher BMI, the use of a walking aid, contralateral knee pain and advanced age were significantly associated with worse physical function $(p<0.05)$ and contributed to $17 \%$ of the variance of the SF-36 HRQoL physical functioning score (multiple $r=0.4 \mathrm{I}$ ).

Conclusion: Patients waiting for knee replacement have poor function and HRQoL. Characteristics that were found to be associated with these outcomes could help develop pre-surgery rehabilitation program and prioritize patients that may benefit the most from them. Such programs could include interventions to reduce psychological distress, therapeutic exercises targeting both knees and weight loss management.
\end{abstract}




\section{Background}

Knee replacement surgery is a common surgical procedure that allows for an effective reduction of pain and adequate restoration of function for the vast majority of patients suffering from advanced knee osteoarthritis or other forms of arthritis. [1] In the last decades, the growing needs of the population have made this procedure, along with hip replacement, the second most popular orthopaedic surgery. [2] In Canada, in 2006, the rate of knee replacements reached 106.9/100 000 persons, in sharp progression from the past decade. [3] This sharp rise in demand has translated into growing waiting lists. Governments have tried to tackle this problem, and with the allocation of new funding and the development of new policies, more patients are being operated. [4] But wait times remain a problem; recent Canadian data show that, depending on the province, the median pre-surgery wait time range from 112 to 291 days and still today an important proportion of patients are not operated within six months, the maximum acceptable waiting time benchmark established in Canada. [5,6]

Waiting for knee replacement surgery represents a significant burden for patients as they experience great pain, suffer functional limitations and loss of health-related quality of life (HRQoL) for many months. Some authors have suggested that long delays for surgery could result in patient's deterioration in terms of pain, functional limitations and HRQoL and may have negative impacts on postsurgery outcomes. [7-9] To lighten the burden of patients waiting for knee replacement, some authors have suggested that reducing wait time is not the only strategy. Some actions should target the reduction of pain and the improvement of function and HRQoL of patients while they are on waiting lists. [10] Two recent studies have shown that education and rehabilitation while waiting for total joint replacement (also called prehabilitation) have positive effects on the patients' health status and could lead to better outcomes postoperatively. [11,12] Until recently prehabilitation was believed to have little effect,[13] but these two studies included a full therapeutic exercises program and were carried out for a longer period of time resulting in more positive outcomes. Therefore, if prehabilitation interventions were efficacious for this population, there is a need to identify factors associated with worse pain, function and HRQoL while waiting for surgery, as it may help develop interventions that target specifically these factors and prioritize patients that may benefit the most from them. To our knowledge, only one Australian study has identified factors associated with increased pain and functional limitations or loss of HRQoL precisely at the inclusion on surgical waiting lists. This study concluded that women had worst function than men and those with lower socioeconomic status had worst HRQoL when entering waiting lists for hip or knee replacement surgery. [14] Other studies have found that factors such as advanced age, female gender, low income, low formal education, long disease duration, high body mass index (BMI), more comorbidities and high use of non-steroidal anti-inflammatory drugs (NSAIDs) were associated with worse pain, function and HRQoL in patients waiting for joint replacement. However, these factors were measured at the time of surgery or during presurgery waiting but not at enrolment on the pre-surgery waiting lists. [15-19]

The objectives of the current study were to measure pain, stiffness, function and HRQoL in patients at enrolment on waiting lists for total knee replacement surgery and to identify demographic, clinical, socioeconomic and psychosocial characteristics associated with these outcomes.

\section{Methods \\ Settings}

This study is part of a broader study measuring the effects of pre-surgery wait in patients scheduled for total knee replacement. From 02/2006 to 09/2007, patients were recruited from the waiting lists of the departments of orthopaedic surgery of three university hospitals in Quebec City, Canada (CHUL, HSFA and HDQ).

\section{Participants}

Every week, patients newly enrolled on the waiting lists were contacted over the phone by a research nurse. To be eligible for the study, patients had to meet the following criteria: 1 -Aged = 40 years; 2 -Newly enrolled on the orthopaedic waiting lists for primary unilateral total knee replacement; 3- Residents of the province of Quebec and beneficiaries of the provincial universal health insurance coverage (Régie de l'Assurance Maladie du Québec RAMQ); 4- Understand and speak French. Patients were excluded if they presented severe cardiac condition, degenerative disease or mental disorder. Patients with a previous contralateral knee or a hip replacement were also excluded. Those who suffered a major trauma to the knee in the previous year or were operated urgently within 30 days of being put on the waiting list were also excluded.

\section{Data collection}

Data were collected through the review of the subjects' medical files and structured telephone interviews conducted within three weeks of the enrolment on waiting lists. The interviews lasted about 45 minutes. Daily attempts were made during weekdays and week-ends to contact new patients.

The first dependent variable was the Western Ontario and McMaster Osteoarthritis Index (WOMAC), which measures pain, stiffness and functional limitations related to the knee. [20] The 5-point Likert version was used. The 
WOMAC scores were transformed in order to obtain a range from 0 to 100 , where a score of 100 indicated no pain, no stiffness or any functional limitations. This transformation allowed for an easier comparison with the SF36 . The WOMAC has been found to have very good reliability, convergent construct validity and responsiveness, and has been used extensively in patients suffering from knee osteoarthritis or undergoing knee replacement. $[21,22]$

The second dependent variable addressed HRQoL, measured with the Medical Outcomes Study 36-Item Short Form Health Survey (SF-36), a generic questionnaire on health status and HRQoL related to eight dimensions of health. [23] It allows for the calculation of two component scales: the physical component scale (PCS) and the mental component scale (MCS) as well as a specific scale for each of the eight health dimensions considered. The scores range from 0 to 100 where a score of 100 indicates optimal HRQoL. The use of the SF-36 has been extensive in population suffering from osteoarthritis[24] and in particular in patients undergoing knee replacement. $[23,25-29]$ The reliability, validity and responsiveness of this self-administered questionnaire have been well established. [30,31]

Anthropometric data were collected through the review of the subjects' medical files after enrolment on the orthopaedic waiting lists and allowed the calculation of the BMI (in $\mathrm{kg} / \mathrm{m}^{2}$ ). Data were typically taken from the pre-operative consultation about 6 weeks before surgery. Patients were also asked about their weight and height at the time of enrolment on the waiting list during the interview. The intraclass correlation coefficient between both measurements was very high (ICC $=0.95 ; 95 \%$ CI: $0.94-0.96$ ).

Marital status, household living status, and clinical variables such as duration of symptoms and use of a walking aid were documented during the interview. Pain in the contralateral knee was assessed using the five questions of the WOMAC pain scale. For analyses, the score was dichotomized (presence or absence of contralateral knee pain). Using the medical files, comorbidities were documented with, the Cumulative Illness Rating Scale (CIRS). [32] This index measures the burden of chronic illness with a score that ranges from 0 to 56 . This tool has been found to be reliable and valid in various settings. [33-35] Formal education, employment status, household income and social support were measured with questions drawn from the questionnaire of the 1998 Quebec Health Survey. [36] The validated and reliable social support measurement tool has three sections referring to the size of the social network, satisfaction with social life and social integration. [37] Because of time constraint, only the questions regarding the size of the social network were used.
For analyses, the social support score (range: 0-150) was dichotomized around the median score. Psychological distress was established with the modified version of the Psychological Symptom Index (PSI), that measures depression and anxiety (range: 0-42). [38] Its French translation has been previously validated by Préville et al. (1992) and has been found highly reliable. $[39,40]$

\section{Analyses}

Descriptive statistics were used to summarize the subjects' characteristics, WOMAC and SF-36 scores. Ninety-five percent confidence intervals $(95 \% \mathrm{CI})$ were built around the mean WOMAC pain, stiffness and function score. Means and 95\% CI of the SF-36 eight domain scores and the physical (PCS) and mental (MCS) component summary scores were compared to Canadian age-matched normative data using student t-tests.

Stepwise multiple regression analysis was used to assess the strength of the associations of the independent variables considered with the WOMAC and SF-36 scores. All three sub-scales of the WOMAC were used as dependent variables in separate models. For the SF-36, separate models were built with the physical and mental summary scores as dependent variables, as well as with the three more responsive health domain scores related to physical health: physical functioning, role-physical and bodily pain. [41] Age and gender were forced into all models. Confounding was defined as a change $\geq 10 \%$ in the regression coefficient of at least one independent variable of a model. [42] Significance levels for independent variable selection were set at 0.10 for initial model entry and at 0.05 to remain in the final model. When dependent variables showed non-normal distributions, the scores were transformed into ranks. [43] Residual plots, outliers and multicollinearity of final models were also assessed. Using simple linear regression models, assuming a type I error $(\alpha)$ of 0.05 , power $(1-\beta)$ of 0.80 and standard deviations of $25(\%)$ for the WOMAC score and of $45(\%)$ for the SF36 , sample sizes of 52 and 161 subjects would be needed to detect a $10 \%$ change in the WOMAC and the SF-36 scores, respectively. $[7,28,44]$ A $10 \%$ change in these scores is considered clinically significant. $[45,46]$ Statistical analyses were performed with the SAS software version 9.1 for Windows (SAS Institute Inc, Cary, NC, USA).

\section{Ethics}

The information and consent forms were read over the phone and verbal consent was sought. The information and consent forms were then mailed to the patient and all participants signed and returned the consent form. This procedure allowed for timely data collection right at the enrolment on the orthopaedic waiting list. The study was approved annually by the Research Ethics Boards of all three hospitals. 


\section{Results}

\section{Participants}

Figure 1 presents the flow of patients considered and recruited for this study. Overall, 588 patients were enrolled on the waiting lists during the recruitment period. Thirty-two patients could not be contacted within three weeks of their inclusion on the waiting list and were excluded. Forty-five patients refused to participate before eligibility could be assessed. Once the remaining patients were assessed, 291 were found not eligible: 182 had a previous knee or hip replacement, 57 were operated within a month and 52 were excluded on other criteria. This left us with 220 eligible subjects, of whom 197 accepted to participate. The 45 patients who refused to participate before eligibility was assessed were included in the calculation of the overall eligibility proportion, $(220+32) /(588-45)=$ 0.464 and in the calculation of the participation proportion, $197 /(220+(45 \times 0.464))=81.8 \%$.

\section{Subjects' characteristics}

Table 1 presents selected characteristics of the participants. Subjects had a mean age of $67 \pm 9.8$ years. The majority was composed of women (64\%) that were married or living in common law (63\%). The mean BMI was $31.0 \mathrm{~kg} / \mathrm{m}^{2}$, indicating a high frequency of obesity defined at $\geq 30 \mathrm{~kg} / \mathrm{m}^{2}$ ). [47] Psychological distress was low, with a mean score of 6.9/42 when compared to the Quebec population mean $(16.23 \pm 14.94)$. [48]

\section{WOMAC pain, stiffness and function}

Participants presented important pain, stiffness and loss of physical function as measured by the WOMAC: the mean pain score was 47.5 (95\% CI: 44.9 - 50.1), the stiffness score was 42.8 (95\% CI: 39.8 - 45.8) and the function score was 47.1 (95\% CI: 45.1 - 49.2).

\section{SF-36 health-related quality of life}

Summary measures of the SF-36 are presented in Table 2. Participants scored significantly lower $(\mathrm{p}<0.05)$ in all eight domains of the SF-36 than the age matched adults of the general Canadian population. [49] Likewise, for the two component summary scales, the subjects' scores were significantly lower $(\mathrm{p}<0.05)$ than the Canadian means.

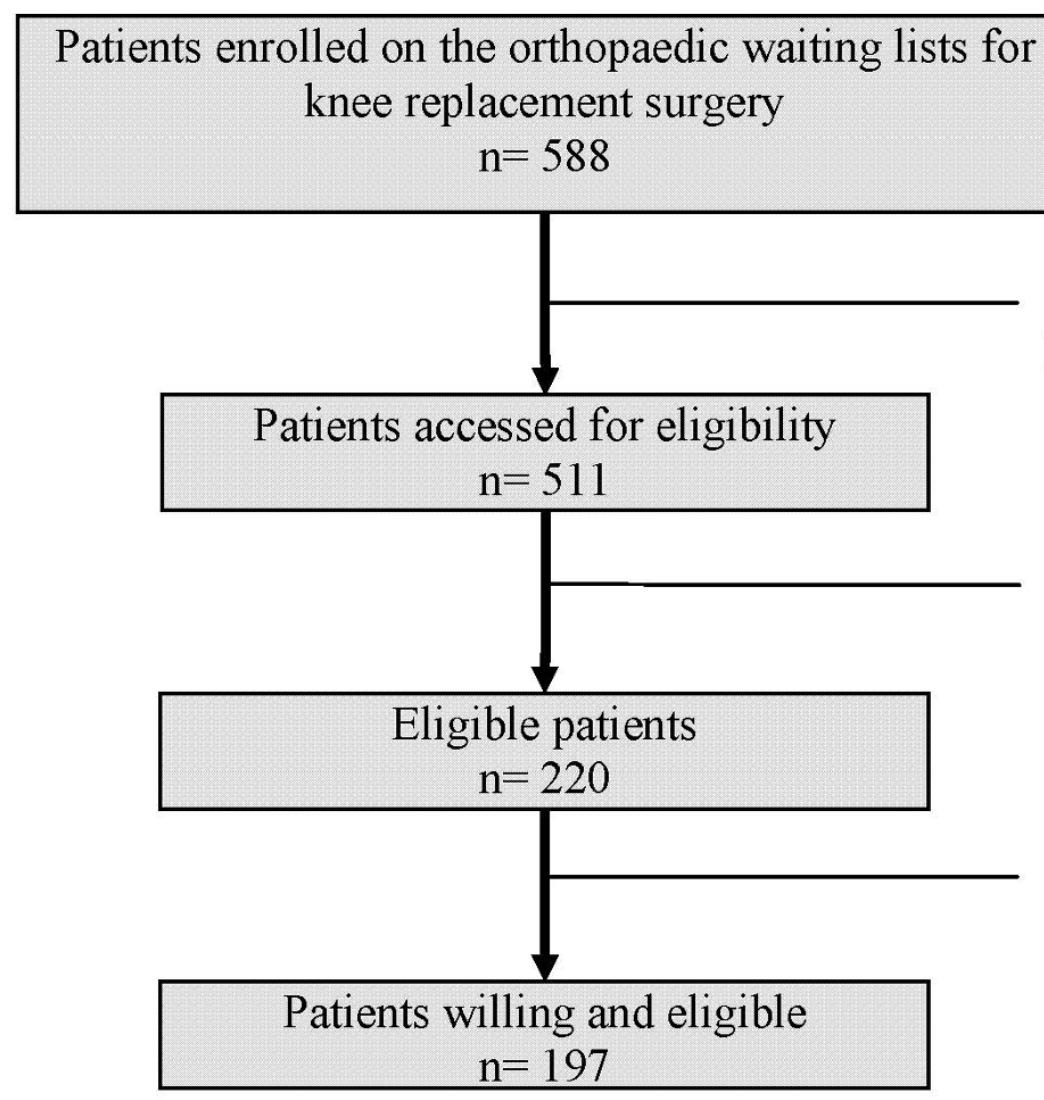

\section{Not reached}

$\mathrm{n}=32^{*}$

Declined study participation

$\mathrm{n}=45^{*}$

Found to be ineligible:

Previous knee or hip replacement

$$
\mathrm{n}=182
$$

Operated within a month $\mathrm{n}=57$

Other reasons $n=52$

\section{Declined study \\ participation \\ $\mathrm{n}=23$}

Figure I

Flowchart of patients' recruitment. * Eligibility status unknown (considered in calculation of participation proportion). 
Table I: Characteristics of the study participants at enrolment on the waiting lists for total knee replacement $(n=197)$

\begin{tabular}{|c|c|c|}
\hline Variables & n (\%) & Mean (SD) \\
\hline \multicolumn{3}{|l|}{ Demographics } \\
\hline Age (years) & & $67(9.8)$ \\
\hline \multicolumn{3}{|l|}{ Gender } \\
\hline Female & $126(64)$ & \\
\hline Male & $71(36)$ & \\
\hline \multicolumn{3}{|l|}{ Marital status } \\
\hline Single, separated, divorced or widowed & $72(37)$ & \\
\hline Married or common law & $125(63)$ & \\
\hline \multicolumn{3}{|l|}{ Living situation } \\
\hline Living alone & $45(23)$ & \\
\hline Not living alone & $152(77)$ & \\
\hline \multicolumn{3}{|l|}{ Clinical characteristics } \\
\hline BMI* $\left(\mathrm{kg} / \mathrm{m}^{2}\right)$ & & $31.0(6.3)$ \\
\hline Comorbidities** (/56) & & $6.2(2.3)$ \\
\hline Duration of symptoms (years) & & $8.5(8.8)$ \\
\hline \multicolumn{3}{|l|}{ Contralateral knee pain ${ }^{\dagger}$} \\
\hline Yes & $53(27)$ & \\
\hline No & $144(73)$ & \\
\hline \multicolumn{3}{|l|}{ Use of a walking aid } \\
\hline Yes & $74(38)$ & \\
\hline No & $123(62)$ & \\
\hline \multicolumn{3}{|l|}{ Socioeconomic characteristics } \\
\hline \multicolumn{3}{|l|}{ Educational level (part or complete) } \\
\hline High school or less & $112(57)$ & \\
\hline College or university & $85(43)$ & \\
\hline \multicolumn{3}{|l|}{ Employment status } \\
\hline Retired & $128(65)$ & \\
\hline Employed & $39(20)$ & \\
\hline Not working or sickness benefit & $30(15)$ & \\
\hline \multicolumn{3}{|l|}{ Household income $\ddagger$} \\
\hline$<\$ 30000 /$ year & $61(36)$ & \\
\hline$\geq \$ 30000 /$ year & $107(64)$ & \\
\hline \multicolumn{3}{|l|}{ Psychosocial characteristics } \\
\hline Psychological distress (/42) & & $6.9(6.5)$ \\
\hline \multicolumn{3}{|l|}{ Social support $\$$} \\
\hline Low & $92(47)$ & \\
\hline High & $105(53)$ & \\
\hline
\end{tabular}

* Body mass index

** Cumulative illness rating scale (CIRS); $\mathrm{n}=177$

t Established from the WOMAC pain score for the contralateral knee

$\ddagger \mathrm{n}=168$

$\S$ Social support was dichotomized around the median score: Low $(\leq 80)$ and High $(>80)$

\section{Multivariate Regression Analyses}

Because no important differences were found in the selection of independent variables between the initial models and the models in which the dependent variables were transformed into ranks, the final models were built with untransformed scores. Age and sex were forced into all models and no other adjustments of confounding variables were necessary.

WOMAC pain, stiffness and function Results of multivariate analyses on the WOMAC scores are presented in Table 3. Contralateral knee pain, higher psychological distress and higher BMI were significantly asso- ciated with worse knee pain $(\mathrm{p}<0.05)$ and explained $11 \%$ of the variance of the WOMAC pain score (multiple correlation coefficient $r=0.33$ ). Contralateral knee pain and higher psychological distress were significantly associated with more knee stiffness $(\mathrm{p}<0.05)$. Longer duration of knee symptoms was significantly associated with less knee stiffness $(p=0.003)$. These three subjects' characteristics explained $11 \%$ of the variance of the WOMAC stiffness score (multiple $r=0.33$ ). Contralateral knee pain, higher psychological distress, higher BMI and use of a walking aid were significantly associated with worse knee function ( $p<0.05$ ) and explained $22 \%$ of the variance of the WOMAC function score (multiple $r=0.47$ ). 
Table 2: Health-related quality of life of the study participants and comparison with Canadian normative data $(n=197)$

\begin{tabular}{|c|c|c|c|c|}
\hline & Mean scoret(SD) & $95 \% \mathrm{Cl}$ & $\begin{array}{l}\text { SF-36 Canadian normative data } \ddagger \\
\text { (Mean and SD) }\end{array}$ & $95 \% \mathrm{Cl}$ \\
\hline \multicolumn{5}{|l|}{ SF-36 } \\
\hline Physical functioning & $24.3(17.9)^{*}$ & $21.8-26.8$ & $75.7(22.2)$ & $74.9-76.5$ \\
\hline Role-physical & $39.3(25.6)^{*}$ & $35.7-42.9$ & $76.2(36.5)$ & $74.9-77.5$ \\
\hline Bodily pain & $27.5(11.7)^{*}$ & $25.8-29.1$ & $74.0(23.9)$ & $73.1-74.8$ \\
\hline General health & $37.1(10.4)^{*}$ & $35.6-38.6$ & $73.5(18.4)$ & $72.8-74.1$ \\
\hline Vitality & $39.5(13.4)^{*}$ & $37.6-41.4$ & $67.7(18.1)$ & $67.0-68.3$ \\
\hline Social functioning§ & $40.9(15.2)^{*}$ & $38.8-43.0$ & $87.0(19.8)$ & $86.2-87.7$ \\
\hline Role-emotional\$ & $69.8(26.3)^{*}$ & $66.1-73.5$ & $83.4(32.8)$ & $82.2-84.6$ \\
\hline Mental health§ & $53.4(I I .4)^{*}$ & $51.8-55.0$ & $79.3(15.0)$ & $78.8-79.8$ \\
\hline Physical component scale (PCS)§ & $28.2(6.4)^{*}$ & $27.3-29.1$ & $47.2(9.7)$ & $46.8-47.6$ \\
\hline Mental component scale (MCS)§ & $42.9(8.1)^{*}$ & $41.7-44.0$ & $53.7(8.3)$ & $53.4-54.0$ \\
\hline
\end{tabular}

† A higher score signs a better health-related quality of life

$\ddagger$ Age matched normative data

$\S \mathrm{n}=196$

* Significantly lower (worse) than the Canadian normative data, $\mathrm{p}<0.05$

\section{SF-36 health-related quality of life}

Results of multivariate analyses on the SF-36 scores are presented in Table 4. Higher BMI, use of a walking aid, contralateral knee pain and advanced age were significantly associated with worse HRQoL related to physical functioning $(\mathrm{p}<0.05)$ and explained $17 \%$ of the variance of this score (multiple $r=0.41$ ). Use of a walking aid, higher psychological distress and comorbidities were significantly associated with worse HRQoL due to physical role limitations $(\mathrm{p}<0.05)$. Married subjects had significantly better HRQoL related to physical role limitations

Table 3: Associations between the study participants' characteristics and the WOMAC scores $(n=197)$

\begin{tabular}{|c|c|c|c|}
\hline WOMAC SCORE $†$ & $\beta^{\ddagger}$ & $95 \% \mathrm{Cl}$ & p value \\
\hline \multicolumn{4}{|l|}{ Pain score $\left(r^{2}=0.1 I\right)$} \\
\hline Contralateral knee pain & -7.65 & $-14.56--3.29$ & $0.009 *$ \\
\hline Psychological distress & -0.45 & $-0.83--0.07$ & $0.020 *$ \\
\hline BMI§ & -0.46 & $-0.86--0.05$ & $0.026 *$ \\
\hline \multicolumn{4}{|l|}{ Stiffness score $\left(r^{2}=0.1 \mathrm{I}\right)$} \\
\hline Contralateral knee pain & -10.07 & $-16.60--3.54$ & $0.003^{*}$ \\
\hline Duration of symptoms & 0.53 & $0.18-0.87$ & $0.003 *$ \\
\hline Psychological distress & -0.55 & $-1.00--0.11$ & $0.015^{*}$ \\
\hline \multicolumn{4}{|l|}{ Function score $\left(r^{2}=0.22\right)$} \\
\hline Contralateral knee pain & -7.18 & $-11.43--2.93$ & $0.00 I^{*}$ \\
\hline Psychological distress & -0.53 & $-0.82--0.24$ & $0.004^{*}$ \\
\hline BMI & -0.42 & $-0.72--0.12$ & $0.006^{*}$ \\
\hline Use of a walking aid & -4.81 & $-8.70--0.94$ & $0.015^{*}$ \\
\hline
\end{tabular}

\footnotetext{
† Stepwise multiple regression analysis. Age and gender were forced into all models.

$\ddagger$ Multivariate unstandardized linear regression coefficients. For each unit of the participants' characteristics, there is in average a $\beta$ increase

$(+)$ or a decrease $(-)$ on the WOMAC score. A positive $\beta$ has a positive effect on the participants' condition and a negative $\beta$ has a negative effect.

$* p<0.05$

$\S \mathrm{BMI}=$ Body mass index
}

than single, separated, divorced or widowed subjects $(\mathrm{p}=$ $0.025)$. Together, these four characteristics explained $17 \%$ of the variance of the role-physical score (multiple $\mathrm{r}=$ 0.41 ). Use of a walking aid was the only characteristic associated with bodily pain and explained $5 \%$ of the variance of this score (multiple $r=0.22$ ).

For the physical component scale, use of a walking aid and higher BMI were significantly associated with worse physical HRQOL and explained $8 \%$ of the variance of this score (multiple $r=0.28$ ). Higher psychological distress, low social support and contralateral knee pain were significantly associated with worse mental HRQoL and explained $42 \%$ of the variance of the mental component score (multiple $r=0.65$ ).

\section{Discussion}

In this cross-sectional study, 197 patients were recruited at the time of enrolment on waiting lists for total knee replacement to measure pain, stiffness, function and HRQoL and to identify demographic, clinical, socioeconomic and psychosocial characteristics associated with these outcomes. We found that subjects reported important pain, stiffness and loss of function. HRQoL was also significantly impaired in these subjects, compared to the Canadian norms, for all the domains and components measured. These findings likely reflect the surgical indication of the subjects' condition. Interestingly however, mental aspects of HRQoL were also impaired. This finding may have implication regarding prehabilitation interventions for these patients, since it suggests that it might be beneficial to include mental health interventions to better help these patients. It is coherent with previous evidence that show that good mental health is a protective factor of functional decline in subjects suffering from knee osteoarthritis. [50] 
Table 4: Associations between the study participants' characteristics and the SF-36 health-related quality of life scores $(\mathrm{n}=197)$

\begin{tabular}{|c|c|c|c|}
\hline SF-36 SCORE $\dagger$ & $\beta \ddagger$ & $95 \% \mathrm{Cl}$ & $p$ value \\
\hline \multicolumn{4}{|l|}{ Physical functioning $\left(r^{2}=0.17\right)$} \\
\hline BMI§ & -0.69 & $-1.10--0.29$ & $<0.00 I^{*}$ \\
\hline Use of a walking aid & -8.28 & $-|3.25--3.3|$ & $0.00 I^{*}$ \\
\hline Contralateral knee pain & -6.03 & $-11.37--0.69$ & $0.027^{*}$ \\
\hline Age & -0.26 & $-0.52--0.01$ & $0.049 *$ \\
\hline \multicolumn{4}{|l|}{ Role-physical $\left(r^{2}=0.17\right)$} \\
\hline Use of a walking aid & -15.23 & $-22.42--8.06$ & $<0.001 *$ \\
\hline Psychological distress & -0.71 & $-1.23--0.18$ & $0.008^{*}$ \\
\hline Marital status (Married or common law) & 8.47 & $1.08-15.85$ & $0.025^{*}$ \\
\hline Comorbidities & -1.46 & $-2.95--0.03$ & $0.044^{*}$ \\
\hline \multicolumn{4}{|l|}{ Bodily pain $\left(r^{2}=0.05\right)$} \\
\hline Use of a walking aid & -3.85 & $-7.27--0.44$ & $0.027^{*}$ \\
\hline \multicolumn{4}{|l|}{ Physical component scale - PCS $\left(r^{2}=0.08\right)^{\circ}$} \\
\hline Use of a walking aid & -2.90 & $-4.78--1.02$ & $0.003^{*}$ \\
\hline BMI & -0.17 & $-0.32--0.02$ & $0.030 *$ \\
\hline \multicolumn{4}{|l|}{ Mental component scale - MCS $\left(r^{2}=0.42\right)^{\circ}$} \\
\hline Psychological distress & -0.74 & $-0.88--0.60$ & $<0.001 *$ \\
\hline Low social support & -2.28 & $-4.14--0.41$ & $0.017^{*}$ \\
\hline Contralateral knee pain & -2.60 & $-4.61--0.59$ & $0.011 *$ \\
\hline
\end{tabular}

† Stepwise multiple regression analysis. Age and gender were forced into all models.

¥ Multivariate unstandardized linear regression coefficients. For each unit of the participants' characteristics there is on average a $\beta$ increase $(+)$ or a decrease (-) on the SF-36 score. A positive $\beta$ has a positive effect on the participants' condition and a negative $\beta$ has a negative effect.

$* \mathrm{p}<0.05$

$\S \mathrm{BMI}=$ Body mass index

${ }^{\circ} \mathrm{n}=196$

We believe that one very interesting finding of our study is that contralateral knee pain is associated with worse pain, stiffness, function and HRQoL related to the knee scheduled for replacement surgery. Although no studies have formally identified this kind of association, from a clinical point of view, it seems logical that patients suffering from both knees have a worse condition. Only one study by Merle-Vincent (2007) has looked at that specific factor but the authors did not find a significant association. [18] Clearly, further research is needed to evaluate the effects of bilateral knee pain on patient's status and outcomes while waiting, as well as after knee replacement surgery. However, this phenomenon may have important clinical implication, as conservative treatment in patients waiting for knee replacement could realistically target both knees to maximize patients' status.

Psychological distress was low in this cohort of patients waiting for knee replacement surgery. Nonetheless, it was significantly associated with worse pain, stiffness, function and HRQoL. Other studies have outlined the important role of psychological distress on the health status of patients suffering from knee pain or undergoing knee replacement surgery. $[14,17]$ High BMI was also significantly associated with worse pain, function and HRQoL. Other studies have found that BMI is a risk factor for the incidence and progression of knee osteoarthritis [51] and that it is also related to post-operative outcomes. $[15,28]$
In terms of treatment, weight-loss therapy and exercise have been found to be beneficial for this population and could be an important component of a prehabilitation program. [52]

Low social support was significantly associated with worse mental HRQoL in our study. This finding is compatible with the results published by Ethgen et al. (2004), who found a significant association between social support and mental and physical aspects of HRQoL in subjects suffering from knee osteoarthritis. These authors recommended that physical health interventions should also add a social support component to improve health outcomes in these patients. [53] In our study, subjects married or living in common-law had a better HRQoL compared to single, separated, divorced or widowed subjects. Further adjustment of this regression model with social support did not change the strength of the association between marital status and the role-physical component of HRQoL. Therefore, we believe that this association is more likely to be related to the help of the spouse on coping skills than to an effect of social support. [54]

Contrary to what other studies found, sociodemographic factors were not related to pain, stiffness, function or HRQoL in our study. This may results from the fact that in this cohort of Canadian patients, access to surgery is equitable as it is not diminished in subjects of lower socioeco- 
nomic backgrounds nor that workers are fast tracked to see the surgeon. $[14,16,55]$

Although the association between longer duration of symptoms and knee stiffness found in our study was small, it is unclear why subjects with longer duration would show less stiffness. Maybe it results from a response shift and possible adaptation to the chronic condition of knee osteoarthritis or arthritis. [56] However this would potentially reflect also in the other sections of the WOMAC, an effect we did not observe.

Several factors were significantly associated with increased pain, stiffness, loss of function and loss of HRQoL in the study subjects. One of the strengths of our study is that many of these independent factors have a consistent effect across the scales of the WOMAC or the SF-36, which further supports the validity of our results. Other strengths include a high participation proportion $(81.7 \%)$, thorough and relevant independent variables selection and no indication of selection bias (there were no significant differences between participants and eligible non participants on age and gender (data not shown). The regression models were adjusted for age and gender and further adjustments with other potential confounding factors only marginally changed the strength of the associations and were therefore not kept in the final models.

This study used a cross-sectional design and therefore caution is warranted when interpreting our results. Hypothesis related to the causality of the different independent variables on patients' health status need to be validated prospectively. Nonetheless, we believe our results provide valuable information regarding the patients' condition right at their enrollment on pre-surgery waiting list for knee replacement.

Another limitation was that the main outcome measures were self-reported and we did not include performancebased measures. The WOMAC and the SF-36 have been found to be valid instruments; still, it has been reported that performance-based measures provide distinct impressions of pain and function that complement self-reported measures. [57] Therefore, the associations or strength of associations between patients' characteristics and performance-based measures could be different from the findings of our study. Although we found a significant association between low social support and worse mental HRQoL, the social support measure only reflected the size of the social network and not the two other components of social support. Therefore associations or strength of associations with the full validated social support measurement tool could be different. It is important to point out that this study focused on patients scheduled for primary unilateral knee replacement and excluded patients undergoing a revision or with a previous contralateral knee replacement or with a hip replacement, therefore results may differ for these patients.

\section{Conclusion}

As seen in this cohort or elsewhere in other Canadian provinces or countries, patients will be waiting for many months, often for more than six months with severe pain, loss of function and poor HRQoL. [6] We acknowledge that actions should be taken to alleviate the burden of patients by reducing wait times but with the growing needs for this surgery, allocation of more resource for surgery alone is unlikely to reach its goal. We believe that other actions are needed to improve pain, function and HRQoL of patients while they are on waiting lists. Although more research is needed to evaluate the full effects of the characteristics identified in the current study, the results of the current study could help identify subjects most in need of prehabilitation and thus may be useful to prioritize patients. Pre-operative assessment already takes place a few weeks before surgery; some of the resource used there could be diverted to meet with patients at the enrollment on the orthopedic wait lists. Patients showing a high BMI, bilateral knee pain, lower social support, poorer HRQoL mental health or high psychological distress could be identified right away and enrolled on a prehabilitation programs while they wait. Further research is needed to evaluate the effects of prehabilitation interventions targeting this population of patients or these factors specifically and could lead to a new model of care for these patients.

\section{Competing interests}

The authors declare that they have no competing interests.

\section{Authors' contributions}

This paper reports part of the doctoral dissertation in Epidemiology of FD, realized under the supervision of CED and the co-supervision of RB. FD participated in the design, coordination and collection of data. He performed the statistical analyses, led the interpretation of results and drafted the manuscript. CED participated in the design, coordination, interpretation of results and writing of the manuscript. EB participated in the design, coordination and writing of the manuscript. RB participated in the design and writing of the manuscript. PF participated in the collection of data and the writing of the manuscript. All authors read and approved the final version of the paper.

\section{Acknowledgements}

F Desmeules is supported by a training fellowship from the Canadian Institutes of Health Research (CIHR). CE Dionne is a senior Quebec Health Research Fund (FRSQ) scholar. The URESP research unit is funded by FRSQ through an infrastructure grant. 


\section{References}

I. Forrest G, Fuchs M, Gutierrez A, Girardy J: Factors affecting length of stay and need for rehabilitation after hip and knee arthroplasty. J Arthroplasty 1998, I3(2): 186-190.

2. Brady OH, Masri BA, Garbuz DS, Duncan CP: Rheumatology: 10. Joint replacement of the hip and knee - when to refer and what to expect. Cmaj 2000, I63(I 0):|285-I29|.

3. The Canadian Institute for Health Information: Canadian Joint Replacement Registry (CJRR) 2007 Annual Report: Hip and Total Knee Replacements in Canada. Ottawa, Ont: CIHI; 2008.

4. The Canadian Institute for Health Information: Surgical Volume Trends, 2008 - Within and Beyond Wait Time Priority Areas. Ottawa, Ont: ClHI; 2008.

5. Noseworthy T, Sanmartin C, Bohm E, Conner-Spady B, DeCoster C, Dumbar M, Lorenzetti D, McLaren L, McGurran J: Towards establishing evidence-based benchmarks for acceptable waiting times for joint replacement surgery-Report 2. Calgary: University of Calgary; 2005:56.

6. The Canadian Institute for Health Information: Wait Times Tables - A Comparison by Province, 2008. Ottawa, Ont: CIHI; 2008.

7. Fortin PR, Clarke AE, Joseph L, Liang MH, Tanzer M, Ferland D, Phillips $\mathrm{C}$, Partridge AJ, Belisle $\mathrm{P}$, Fossel $\mathrm{AH}$, et al.: Outcomes of total hip and knee replacement: preoperative functional status predicts outcomes at six months after surgery. Arthritis Rheum 1999, 42(8): | 722-| 728.

8. Fortin PR, Penrod JR, Clarke AE, St-Pierre Y, Joseph L, Belisle P, Liang $\mathrm{MH}$, Ferland $\mathrm{D}$, Phillips $\mathrm{CB}$, Mahomed $\mathrm{N}$, et al: Timing of total joint replacement affects clinical outcomes among patients with osteoarthritis of the hip or knee. Arthritis Rheum 2002 46(12):3327-3330.

9. Ashworth A, Brulé C, Day A, Harrison M, Hopman W, Rudan J: The Development of an Orthopedic Waiting List Algorithm for Elective Total Hip and Total Knee Replacement Surgery. Canadian Health Services Research Foundation; 2002:44.

10. Landry MD, Jaglal SB, Wodchis WP, Cooper NS, Cott CA: Rehabilitation services after total joint replacement in Ontario, Canada: can 'prehabilitation' programs mediate an increasing demand? Int J Rehabil Res 2007, 30(4):297-303.

II. Nunez M, Nunez E, Segur JM, Macule F, Quinto L, Hernandez MV, Vilalta $C$ : The effect of an educational program to improve health-related quality of life in patients with osteoarthritis on waiting list for total knee replacement: a randomized study. Osteoarthritis Cartilage 2006, I 4(3):279-285.

12. Rooks DS, Huang J, Bierbaum BE, Bolus SA, Rubano J, Connolly CE, Alpert S, Iversen MD, Katz JN: Effect of preoperative exercise on measures of functional status in men and women undergoing total hip and knee arthroplasty. Arthritis Rheum 2006, 55(5):700-708.

13. McDonald S, Hetrick S, Green S: Pre-operative education for hip or knee replacement. Cochrane Database Syst Rev 2004:CD003526.

14. Ackerman IN, Graves SE, Wicks IP, Bennell KL, Osborne RH: Severely compromised quality of life in women and those of lower socioeconomic status waiting for joint replacement surgery. Arthritis Rheum 2005, 53(5):653-658.

15. Nunez M, Nunez E, Segur JM, Macule F, Sanchez A, Hernandez MV Vilalta $C$ : Health-related quality of life and costs in patients with osteoarthritis on waiting list for total knee replacement. Osteoarthritis Cartilage 2007, I 5(3):258-265

16. Davis ET, Lingard EA, Schemitsch EH, Waddell JP: Effects of socioeconomic status on patients' outcome after total knee arthroplasty. Int J Qual Health Care 2008, 20(I):40-46

17. Hirvonen J, Blom M, Tuominen U, Seitsalo S, Lehto M, Paavolainen $P$ Hietaniemi K, Rissanen P, Sintonen H: Health-related quality of life in patients waiting for major joint replacement. A comparison between patients and population controls. Health Qual Life Outcomes 2006, 4:3.

18. Merle-Vincent F, Couris CM, Schott AM, Perier M, Conrozier S, Conrozier T, Piperno M, Mathieu P, Vignon E: Cross-sectional study of pain and disability at knee replacement surgery for osteoarthritis in 299 patients. Joint Bone Spine 2007, 74(6):612-616.

19. Tuominen U, Blom M, Hirvonen J, Seitsalo S, Lehto M, Paavolainen P, Hietanieni K, Rissanen P, Sintonen $\mathrm{H}$ : The effect of co-morbidities on health-related quality of life in patients placed on the waiting list for total joint replacement. Health Qual Life Outcomes 2007, 5:16.
20. Bellamy N, Buchanan WW: A preliminary evaluation of the dimensionality and clinical importance of pain and disability in osteoarthritis of the hip and knee. Clin Rheumatol 1986, 5(2):23|-24I

21. Bellamy N, Campbell J, Hill J, Band P: A comparative study of telephone versus onsite completion of the WOMAC 3.0 osteoarthritis index. J Rheumatol 2002, 29(4):783-786.

22. McConnell S, Kolopack P, Davis AM: The Western Ontario and McMaster Universities Osteoarthritis Index (WOMAC): a review of its utility and measurement properties. Arthritis Rheum 200I, 45(5):453-46I

23. Ware JE Jr, Sherbourne CD: The MOS 36-item short-form health survey (SF-36). I. Conceptual framework and item selection. Med Care 1992, 30(6):473-483.

24. Keller SD, Majkut TC, Kosinski M, Ware JE Jr: Monitoring health outcomes among patients with arthritis using the SF-36 Health Survey: overview. Med Care 1999, 37(5 Suppl):MSI-9.

25. Bombardier C, Melfi CA, Paul J, Green R, Hawker G, Wright J, Coyte $P$ : Comparison of a generic and a disease-specific measure of pain and physical function after knee replacement surgery. Med Care 1995, 33(4 Suppl):ASI3I-I44.

26. Jones CA, Voaklander DC, Johnston DW, Suarez-Almazor ME: Health related quality of life outcomes after total hip and knee arthroplasties in a community based population. J Rheumatol 2000, 27(7): I745-I752.

27. Jones CA, Voaklander DC, Johnston DW, Suarez-Almazor ME: The effect of age on pain, function, and quality of life after total hip and knee arthroplasty. Arch Intern Med 200I, I 6 I (3):454-460.

28. Jones CA, Voaklander DC, Suarez-Alma ME: Determinants of function after total knee arthroplasty. Phys Ther 2003, 83(8):696-706

29. Williams Jl, Llewellyn Thomas H, Arshinoff R, Young N, Naylor CD: The burden of waiting for hip and knee replacements in Ontario. Ontario Hip and Knee Replacement Project Team. J Eval Clin Pract 1997, 3( I):59-68.

30. Brazier JE, Harper R, Munro J, Walters SJ, Snaith ML: Generic and condition-specific outcome measures for people with osteoarthritis of the knee. Rheumatology (Oxford) 1999, 38(9):870-877.

31. Lingard EA, Katz JN, Wright EA, Sledge CB: Predicting the outcome of total knee arthroplasty. J Bone Joint Surg Am 2004, 86 A(I 0):2179-2186.

32. Miller MD, Paradis CF, Houck PR, Mazumdar S, Stack JA, Rifai AH, Mulsant B, Reynolds CF 3rd: Rating chronic medical illness burden in geropsychiatric practice and research: application of the Cumulative Illness Rating Scale. Psychiatry Res 1992, 4 I (3):237-248.

33. Hudon C, Fortin M, Vanasse A: Cumulative Illness Rating Scale was a reliable and valid index in a family practice context. Clin Epidemiol 2005, 58(6):603-608.

34. de Groot V, Beckerman H, Lankhorst GJ, Bouter LM: How to measure comorbidity. a critical review of available methods. J Clin Epidemiol 2003, 56(3):221-229.

35. Salvi F, Miller MD, Grilli A, Giorgi R, Towers AL, Morichi V, Spazzafumo L, Mancinelli L, Espinosa E, Rappelli A, et al.: A manual of guidelines to score the modified cumulative illness rating scale and its validation in acute hospitalized elderly patients. I Am Geriatr Soc 2008, 56( I 0): 1926-1931.

36. Daveluy C, Pica L, Audet N, Courtemanche R, Lapointe F: Enquête sociale et de santé 1998. 2e edition. Québec: Institut de la statistique du Québec; 2000.

37. Julien M, Julien D, Lafontaine P: «Environnement de Soutien » Chapitre 25. In Enquête sociale et de santé 1998 2e edition. Québec: Institut de la statistique du Québec; 1998.

38. Ilfeld FW Jr: Further validation of a psychiatric symptom index in a normal population. Psychol Rep 1976, 39:1215-1228.

39. Légaré G, Préville M, Massé R, Poulin C, St-Laurent D, Boyer R: « Santé Mentale » Chapitre I6. In Enquête sociale et de santé 1998 2e edition. Québec: Institut de la statistique du Québec; 1998.

40. Préville M, Boyer R, Potvin L, Perrault C, G L: La détresse psychologique: détermination de la fiabilité et de la validité de la mesure utilisée dans l'Enquête Santé Québec. Les cahiers de la recherche, 7, Enquête Santé Québec 87, Gouvernement du Québec, Ministère de la Santé et des Services Sociaux 1992. 
4I. Ware JE Jr, Kosinski M, Gandek B: SF-36 Health Survey: Manual \& Interpretation Guide. Lincoln, RI: QualityMetric Incorporated; 1993:2000.

42. Rothman K, Greenland S: Modern Epidemiology. 2nd edition. Philadelphia: Lippincott Williams \& Wilkins; 1998.

43. Conover W, Iman R: Rank transformations as a bridge between parametric and nonparametric statistics. Am Stat 198I, 35(3): 124-130.

44. Kelly KD, Voaklander DC, Johnston DW, Newman SC, Suarez-Almazor ME: Change in pain and function while waiting for major joint arthroplasty. J Arthroplasty 200I, I6(3):35I-359.

45. Angst F, Aeschlimann A, Stucki G: Smallest detectable and minimal clinically important differences of rehabilitation intervention with their implications for required sample sizes using WOMAC and SF-36 quality of life measurement instruments in patients with osteoarthritis of the lower extremities. Arthritis Rheum 200I, 45(4):384-391.

46. Ehrich EW, Davies GM, Watson DJ, Bolognese JA, Seidenberg BC Bellamy N: Minimal perceptible clinical improvement with the Western Ontario and McMaster Universities osteoarthritis index questionnaire and global assessments in patients with osteoarthritis. J Rheumatol 2000, 27(I I):2635-264I.

47. WHO: Obesity: preventing and managing the global epidemic. Report of a WHO Consultation. WHO Technical Report Series 894. Geneva: World Health Organization; 2000.

48. Boyer R, Preville M, Legare G, Valois P: [Psychological distress in a noninstitutionalized population of Quebec: normative results of the Quebec health survey]. Can J Psychiatry 1993, 38(5):339-343.

49. Hopman WM, Towheed T, Anastassiades T, Tenenhouse A, Poliquin S, Berger C, Joseph L, Brown JP, Murray TM, Adachi JD, et al.: Canadian normative data for the SF-36 health survey. Canadian Multicentre Osteoporosis Study Research Group. Cmaj 2000, 163(3):265-27|.

50. Sharma L, Cahue S, Song J, Hayes K, Pai YC, Dunlop D: Physical functioning over three years in knee osteoarthritis: role of psychosocial, local mechanical, and neuromuscular factors. Arthritis Rheum 2003, 48( I 2):3359-3370.

51. Reijman M, Pols HA, Bergink AP, Hazes JM, Belo JN, Lievense AM, Bierma-Zeinstra SM: Body mass index associated with onset and progression of osteoarthritis of the knee but not of the hip: the Rotterdam Study. Ann Rheum Dis 2007, 66(2): 158-162.

52. Miller GD, Nicklas BJ, Davis C, Loeser RF, Lenchik L, Messier SP: Intensive weight loss program improves physical function in older obese adults with knee osteoarthritis. Obesity (Silver Spring) 2006, I 4(7): 1219-1230.

53. Ethgen O, Vanparijs P, Delhalle S, Rosant S, Bruyere O, Reginster JY: Social support and health-related quality of life in hip and knee osteoarthritis. Qual Life Res 2004, I 3(2):32I-330.

54. Keefe FJ, Blumenthal J, Baucom D, Affleck G, Waugh R, Caldwell DS, Beaupre P, Kashikar-Zuck S, Wright K, Egert J, et al.: Effects of spouse-assisted coping skills training and exercise training in patients with osteoarthritic knee pain: a randomized controlled study. Pain 2004, I I 0(3):539-549.

55. Skinner J, Zhou W, Weinstein J: The influence of income and race on total knee arthroplasty in the United States. J Bone Joint Surg Am 2006, 88( I 0):2159-2166.

56. Ong BN, Hooper H, Jinks C, Dunn K, Croft P: 'I suppose that depends on how I was feeling at the time': perspectives on questionnaires measuring quality of life and musculoskeletal pain. J Health Serv Res Policy 2006, II (2):8I-88.

57. Kennedy DM, Stratford PW, Hanna SE, Wessel J, Gollish JD: Modeling early recovery of physical function following hip and knee arthroplasty. BMC Musculoskelet Disord 2006, 7:100.

\section{Pre-publication history}

The pre-publication history for this paper can be accessed here:

http://www.biomedcentral.com/1471-2474/10/52/pre pub Publish with Bio Med Central and every
scientist can read your work free of charge

"BioMed Central will be the most significant development for disseminating the results of biomedical research in our lifetime. "

Sir Paul Nurse, Cancer Research UK

Your research papers will be:

- available free of charge to the entire biomedical community

- peer reviewed and published immediately upon acceptance

- cited in PubMed and archived on PubMed Central

- yours - you keep the copyright

Submit your manuscript here:

http://www.biomedcentral.com/info/publishing_adv.asp
BioMedcentral 